\title{
Oil spill remedy using bi-axially oriented polymer films
}

\author{
J. Saleem, A. Bazargan, J. Barford \& G. McKay \\ Department of Chemical and Biomolecular Engineering, \\ Hong Kong University of Science and Technology, Hong Kong
}

\begin{abstract}
Oil spill on water surface and shorelines has been a major source of water pollution. With the damaging impact to ecology and the long term effects of environmental pollution, demand for materials for cleaning up the water in a quick and effective way has increased. A number of sorbents have been recommended for the purpose of picking up oil from water. These range from natural products, such as inorganic porous products and organic biodegradable products. However, most of them reveal limited oil sorption capacity and also absorb water. Hence, it is felt that there is a need of producing a synthetic oil sorbent that not only has high sorption capacity but also, unlike other contemporary synthetic sorbents, proves to be strong and cost effective. In this paper, we are presenting a novel super oil sorbent polymer (oil-sap) sheet consisting of ultrahigh molecular weight polyethylene (UHMWPE). The sorbent exhibits an uptake capacity of $(276 \mathrm{~g} / \mathrm{g})$ and pickup density of $\left(58 \mathrm{~g} / \mathrm{cm}^{3}\right)$. In addition, it comprises a mechanically strong structure (tensile modulus and breaking stress of $1332 \mathrm{MPa}$ and $171 \mathrm{MPa}$ respectively). The unique blend of uptake capacity and strength along with cost effectiveness of the raw material (polyethylene) makes these sheets feasible candidates for mass production and application.
\end{abstract}

Keywords: polyethylene, oil spill, modulus, sorption, pickup density.

\section{Introduction}

Water pollution by oil spills is a key threat to the environment. Its damaging effect on the ecology calls for procedures to clean up the spill in a quick and effective way. 
A number of sorbents have been recommended to uptake oil from spill. These range from natural products, such as multifarious inorganic porous products (like talc, clay, zeolites, silica, aerogel, calcium fly ash, etc.) (Arbatan et al. [1] and Karakasi and Moutsatsou [2]) to organic biodegradable products such as straw, hull, corncob, peat moss, sugar cane bagasse, wood/cotton fibers, wool-based stuff, silkworm cocoon waste, etc. (Adebajo and Frost [3] and Chung [4]). However, most of them have drawbacks including limited oil sorption capacities and high water uptake (Chung [4]).

To prevail over these problems, synthetic sorbents like meltblown polypropylene (fiber-based) pads and booms (Bayat et al. [5] and Wei et al. [6]) or relatively thick ( $5 \mathrm{~mm}$ or greater) mats, sheets or rolls of melt-spun and fabricstitched oleophilic polymers have been proposed. Examples of the latter include $3 \mathrm{M}^{\circledR}$ Type 156 pads and ALSORB $^{\circledR}$ sheets or rolls (Herkenberg [7]). More recently, several articles have focused on preparing materials of high oil absorption capacity by using high surface area materials which include nanowire membranes (Yuan et al. [8]), nanocellulose aerogels (Juuso et al. [9] and carbon nanotubes (Gui et al. [10,11]); however these processes typically increase the cost of sorbents. Also synthetic functional polyolefins (Chung [4] and Yuan and Chung [12]) have been proposed with uptake capacities as high as $50 \mathrm{~g} / \mathrm{g}$ oil. Hydrogels (Chung [4], Min et al. [13]) for absorbing aqueous solutions with absorption capacities more than 1000 times the polymer weight have also been made. Unfortunately, these products exhibit water affinity (Chung [4]). Thin flexible polyethylene sheets (Herkenberg [7, 14]) consisting of multiple materials with increased cost and complication in the production process have been shown to exhibit oil sorption values exceeding $200 \mathrm{~g} / \mathrm{g}$. The saturation time reported for these sheets is long, suggesting a slow uptake mechanism.

In order to overcome the disadvantages associated with each of the previous products, our research approach has been focused to prepare an oil sorbent which can simultaneously exhibit a combination of several essential properties, including (a) high oil sorption capacity both in terms of $\mathrm{g} / \mathrm{g}$ and $\mathrm{g} / \mathrm{cm}^{3}$, (b) sufficient mechanical strength for practical applications, and (c) cost effectiveness of raw material.

\section{Methodology}

\subsection{Preparation of oil sorbent}

UHMWPE powder was placed in a vacuum oven for 24 hours and then was dispersed in mineral oil and petrolatum wax in a ratio of 10:45:45 by weight. Antioxidant Irganox 1010 in a ratio of $0.5 \mathrm{wt}$ \% of total weight of mixture was also added. This mixture was heated to $80^{\circ} \mathrm{C}$ with high speed mixing until homogeneity is achieved. The mixture went through a twin screw extruder model where it was heated beyond the melting point of the polymer. Later, it was hotpressed at $200^{\circ} \mathrm{C}$ in order to achieve a flat sheet followed by solvent extraction in a hexane bath for 10 minutes with constant stirring at room temperature to remove around $50-60 \%$ of the solvent. Sheets were later stretched by using 
successive biaxial stretching technique at different stretching ratios using a crosshead speed of $400 \mathrm{~mm} / \mathrm{min}$ at $121^{\circ} \mathrm{C}$. The thus stretched films were placed in boiling hexane to extract and remove the residual solvent and then dried to obtain polyethylene porous films. A similar procedure for material preparation was used regarding fuel cell application (Saleem et al. [15]). The features that make this work distinct are as follows: Stretching temperature used in current study is $121^{\circ} \mathrm{C}$ which is closer to melting temperature of polyethylene and well over $\alpha$-transition temperature. The use of high draw temperature allowed the polymeric chains to slide past each other and facilitate in orientation of chains. Second and the most distinctive difference was the methodology that was adopted for the orientation of polymer chains as this is one of the most important steps in the preparation of porous sheets. In the current methodology some amount of oil was left in gel sheet during extraction and then stretching was performed. The inspiration of this step was taken from (Kono et al. [17]).

According to his approach if the amount of oil in gel sheet is less than $10 \%$, the network structure is decreased and excessive compacting proceeds so that stretching could not be carried out with a high draw ratio and a super-thin film with a higher strength could not be obtained, on the other hand if amount of oil exceeds more than $80 \%$ by weight, the gel sheet is excessively swelled and a high orientation stretching cannot be performed and breaking will occur and the resulting film will have a lower strength. This step suits our application as we need thinnest possible porous film with high mechanical properties in order to get the highest possible uptake capacity.

\subsection{Oil sorption set up}

A specimen of known size was initially weighed dry and was then placed on one face on the surface of bath of diesel oil and allowed to float on the oil for certain period of time. Then it was collected and measured to get the final weight. Oil pick up ratio $(\mathrm{g} / \mathrm{g})$ and oil pick up density $\left(\mathrm{g} / \mathrm{cm}^{3}\right)$ were then calculated.

\subsection{Porosity of the membrane}

The porosity $(\varphi)$ of the membrane was estimated by the following equation:

$$
\varphi \%=1-W /(\rho A \mathrm{~T})
$$

where $\mathrm{W}$ is the dry UHMWPE mass, $\rho$ is the density of UHMWPE, A, T are the area and thickness of the sheet respectively. Mitutoyo micrometer was used to measure thickness.

\subsection{SEM}

JEOL 6700F Scanning Electron Microscopy (SEM) with energy dispersive analysis by X-ray was used to observe the surface of the porous sheets. 


\subsection{Tensile test}

Tensile properties of the membranes were measured using the Advanced Rheometrics Expansion System (ARES) at an extension rate $2 \mathrm{~mm} / \mathrm{min}$ at room temperature. Five samples were used for each test. The tensile modulus was obtained by plotting the stress versus strain. Aluminum foil and A4 sized paper were also tested to give better comparison of mechanical properties. Aluminum foil from Reynolds Wrap ${ }^{\circledR}$ has the thickness of $20 \mu \mathrm{m}$ and weight per unit area of $0.00454 \mathrm{~g} / \mathrm{cm}^{2}$ while printing paper of size A4 from Paperone ${ }^{\circledR}$ has the thickness of $110 \mu \mathrm{m}$ and weight per unit area of $0.008 \mathrm{~g} / \mathrm{cm} 2$. Tensile tests of sheets with different stretching ratios were performed. A stretching ratio of $12 \times 12$ means an elongation of $1100 \%$ whereas $9 \times 9$ and $6 \times 6$ refer to an elongation of $800 \%$ and $500 \%$ respectively. We refer $12 \times 12,9 \times 9$, and $6 \times 6$ samples as S1, S2, and S3 respectively.

\section{Results and discussion}

\subsection{Porosity}

Porosities of the sorbent samples are presented in Table 1. The slight difference in porosities and major difference in thickness is due to the biaxial stretching. The stretching of the polymer modifies both pore shape and size. Pore deformation is known to happen in three stages: (a) initial stretching aligns pores in the direction of force; (b) continued stretching results in uniform deformation of pores; (c) at a critical level of strain small polymer fibrils in the polymer matrix fracture resulting in the formation of macro voids in the polymer (Morehouse et al. [16]).

Table 1: Porosities of as prepared sorbents.

\begin{tabular}{ccc}
\hline Sample & $\begin{array}{c}\text { Thickness } \\
\mu \mathrm{m}\end{array}$ & $\begin{array}{c}\text { Porosity } \\
\%\end{array}$ \\
\hline S1 & 6.3 & 67.1 \\
\hline S2 & 8.0 & 65.5 \\
\hline S3 & 9.3 & 64.6 \\
\hline
\end{tabular}

\subsection{Mechanical properties of UHMWPE composite membranes}

Figure 1 summarizes the mechanical performances of the samples with different stretching ratios. It has been reported that both the Young's modulus and the breaking strength increase with the drawing ratio because of the alignment of polymer chains in the direction of force (Gerrits and Lemstra [18]) and this fact has been validated. Aluminum foil and A4 printing paper were also tested to show the relative comparison both in terms of modulus and breaking strength. From the results it is evident that $\mathrm{S} 1$ is stiffer and stronger than all the other 
materials presented in Figure 1. The strength and durability of the sorbent makes its handling, packaging, transportation, and practical usage easier. It is a crucial point that although the sorbents are extremely lightweight and thin, this does not make them weak.

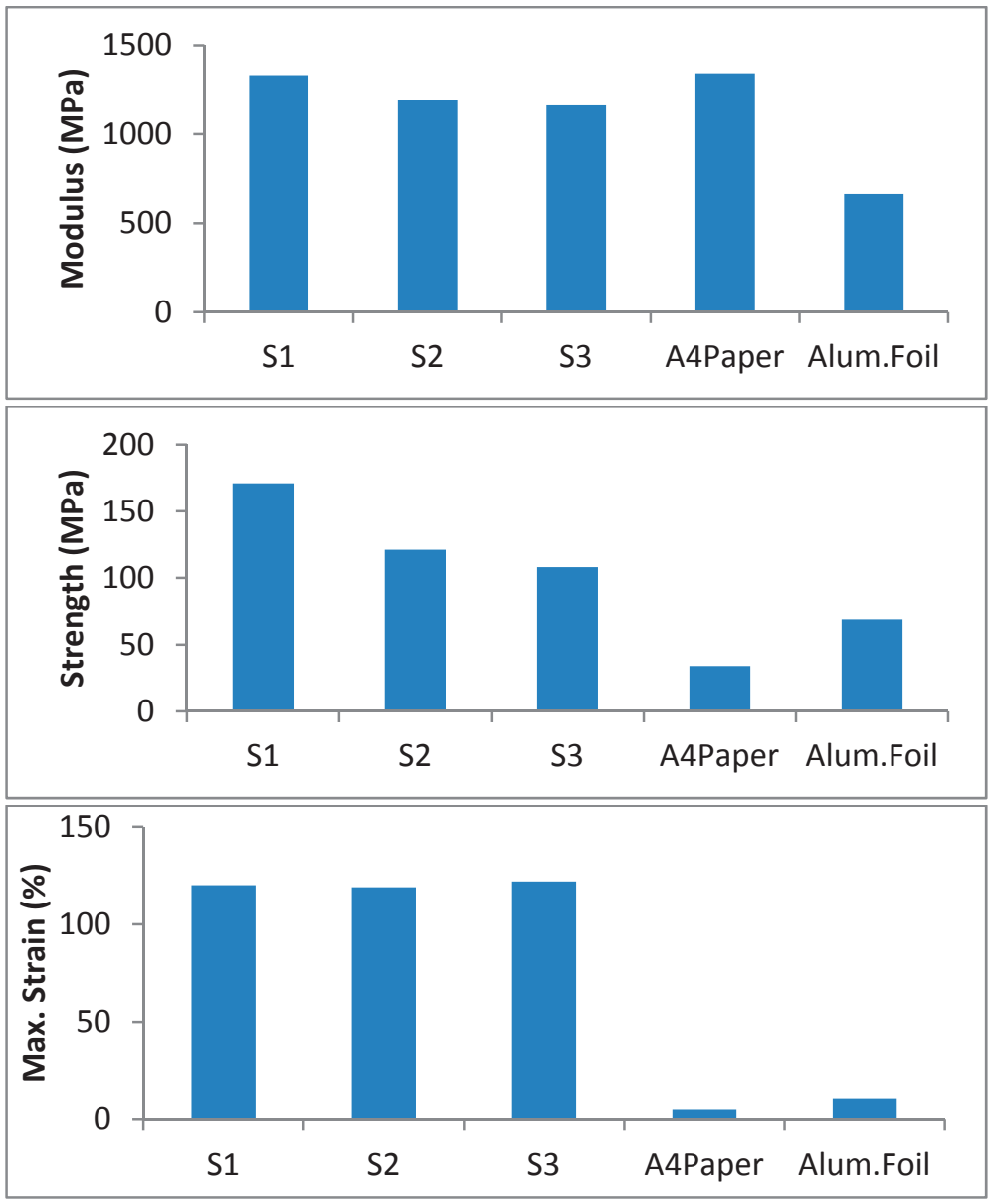

Figure 1: Mechanical properties of UHMWPE films.

\subsection{Oil sorption}

Figure 2 presents the oil sorption capacity of the novel porous sheets measured after 2 minutes of dripping. High oil uptake of our samples is mainly due to the combination of the following: 
(a) high surface to thickness ratio maximizes the uptake value of $\mathrm{g} / \mathrm{g}$ (Hekenberg [7], Harold [19]), and (b) further enhancement of sorption capacity is provided by the presence of pores in the polymer film (Harold [19]). The porous structure allows the oil to penetrate and swell the network without difficulty.

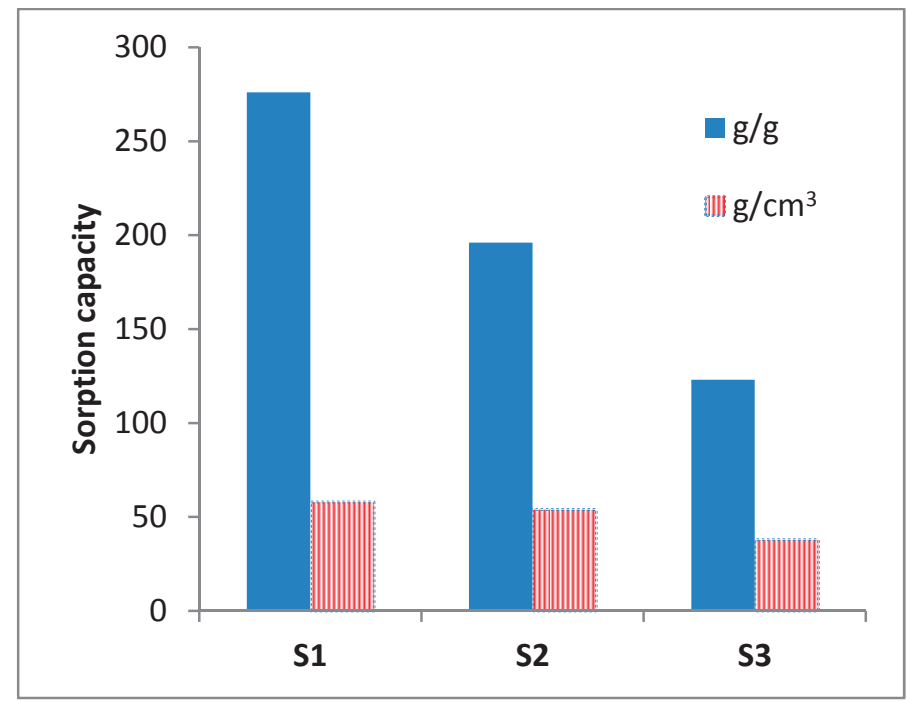

Figure 2: $\quad$ Oil sorption capacities of samples S1, S2, and S3.

Another important parameter in the selection of a sorbent material for use in oil spill applications is the "pick-up density", as it answers the question of how much oil a unit volume of sorbent product can be expected to pick up. This parameter is directly relevant to the ease and efficiency of physically handling of the sorbent product at the deployment site (Herkenberg [7]). The pick-up density is crucial for calculation of a sorbent's real-world application when calculating transportation and storage costs.

\subsection{SEM}

As we found out that sample S1 is stiffer, stronger and has higher sorption capacities than other samples, hence we chose it for SEM. Figure 3 illustrates the porous structure of UHMWPE sheets under the SEM. The pore size is in the range of $30-100 \mathrm{~nm}$. The raw UHMWPE prior to treatment is not porous and the pore structure has been formed due to the removal of the mineral oil and petrolatum wax from the sheet. The pores have enlarged by means of biaxial stretching. 


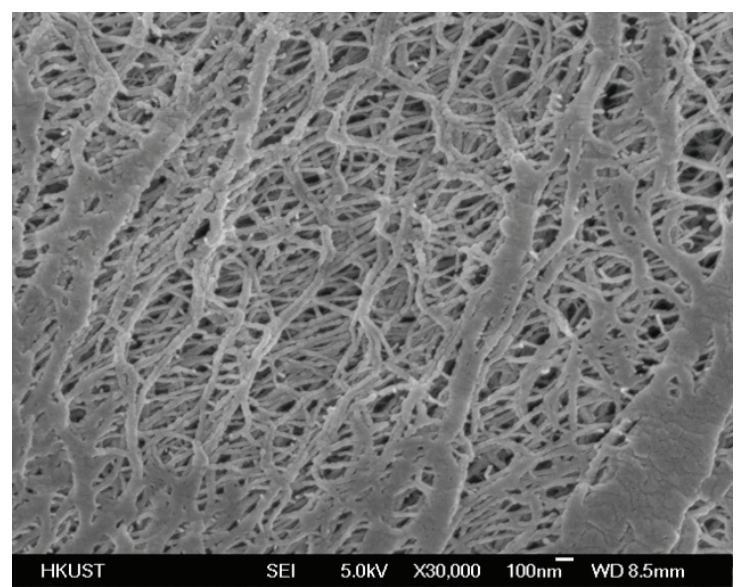

Figure 3: Surface view of UHMWPE sorbent.

\section{Conclusions}

The key goal of this work was to synthesize and test novel porous polymer films which could simultaneously exhibit a combination of several essential properties for oil sorption, including high oil sorption capacity $(\mathrm{g} / \mathrm{g})$, high pick-up density $\left(\mathrm{g} / \mathrm{cm}^{3}\right)$, mechanically strong for practical applications and cheap raw material. The results presented in this work have validated our proposed goals. The sorbent provides a unique blend of sorption capacity as well as improved mechanical properties.

\section{Acknowledgements}

Marine diesel oil was delivered by Gulf Marine Co. with the assistance of Peako Biomass Energy Co. Ltd., Jiangxi, China. UHMWPE (3.5Million molar mass) was supplied by Ticona. Kaydol White Mineral oil and White Protopet 1S Petrolatum were provided by Sonneborn. Irganox ${ }^{\circledR} 1010$ was taken from BASF. The authors would like to acknowledge the financial support from the Hong Kong Research Grant Council (HKRGC). We are also thankful to Prof. Ping Gao of HKUST as well as Mr. Ronnie Lo of Peako Biomass Energy Co. Ltd.

\section{References}

[1] Arbatan, T.; Fang, X.; Shen, W. Superhydrophobic and oleophilic calcium carbonate powder as a selective oil sorbent with potential use in oil spill clean-ups. Chem. Eng. J., 166, 787-791, 2011 
[2] Karakasi, O. K.; Moutsatsou, A. Surface modification of high calcium fly ash for its application in oil spill clean up. Fuel, 89, 3966-3970, 2010

[3] Adebajo, M.; Frost, R. Porous materials for oil spill cleanup: a review of synthesis and absorbing properties. J. Porous Mater., 10, 159-170, 2003

[4] Chung, T. Functional Polyolefins for Energy Applications. Macromolecules 2013, DOI: 10.1021/ma401244t

[5] Bayat, A.; Aghamiri, S. F.; Moheb, A.; Vakili-Nezhaad, G. R. Oil Spill Cleanup from Sea Water by Sorbent Materials. Chem. Eng. Technol., 28, $1525-1528,2005$

[6] Wei, Q. F.; Mather, R. R.; Fotheringham, a F. Oil removal from used sorbents using a biosurfactant. Bioresour. Technol., 96, 331-334, 2005

[7] Herkenberg, W. Method for the removal of oil from oil spills. US Pat. $5,451,3251995$

[8] Yuan, J.; Liu, X.; Akbulut, O.; Hu, J.; Suib, S. L.; Kong, J.; Stellacci, F. Superwetting nanowire membranes for selective absorption. Nat. Nanotechnol. 3, 332-336, 2008

[9] Juuso, T. K.; Kettunen, M.; Ras, R. H. A.; Olli, I. Hydrophobic Nanocellulose Aerogels as Floating, Sustainable, Reusable, and Recyclable Oil Absorbents. ACS Appl. Mater. Interfaces, 3, 1813-1816, 2011

[10] Gui, X.; Li, H.; Wang, K.; Wei, J.; Jia, Y.; Li, Z.; Fan, L.; Cao, A.; Zhu, $\mathrm{H}$.; Wu, D. Recyclable carbon nanotube sponges for oil absorption. Acta Mater. 59, 4798-4804, 2011

[11] Gui, X.; Wei, J.; Wang, K.; Cao, A.; Zhu, H.; Jia, Y.; Shu, Q.; Wu, D. Carbon nanotube sponges. Adv. Mater., 22, 617-621, 2010

[12] Yuan, X.; Chung, T. C. M. Novel Solution to Oil Spill Recovery: Using Thermodegradable Polyolefin Oil Superabsorbent Polymer (Oil-SAP). Energy \& Fuels, 26, 4896-4902, 2012

[13] Min, H. P.; Min, K. J.; Bo, G. C.; Byeongmoon, J. Biodegradable Thermogels. Acc. Chem. Res., 45, 424-433, 2012

[14] Herkenberg, W. Thin flexible sheet sorption material for the removal of oil from oil spills. EP 0507784 B1 1991

[15] Saleem, J.; Gao, P.; Barford, J.; McKay, G. Development and characterization of novel composite membranes for fuel cell applications. J. Mater. Chem. A, 1, 14335-14343 2013

[16] Morehouse, J. A.; Worrel, L. S.; Taylor, D. L.; Lloyd, D. R.; Freeman, B. D.; Lawler, D. F. The effect of uni-axial orientation on macroporous membrane structure. J. Porous Mater., 13, 61-72, 2006

[17] Kono, K., Mori, S., Miyaska, K. and Tabuchi, J. Polyethylene microporous membrane of ultra high molecular weight. US Pat. 4,588,633, 1986.

[18] Gerrits, N. J. A.; Lemstra, P. J. Porous biaxially drawn ultra-high molecular weight polyethylene films. Polymer., 32, 1770-1775, 1991

[19] Harold, E. M. Oil and fat absorbing polymers. US Pat. 4,039,489 1977 